\title{
In vitro Anti-Leishmanial and Anti-Tumour Activities of a Pentacyclic Triterpenoid Compound Isolated from the Fruits of Dregea volubilis Benth Asclepiadaceae
}

\author{
Biswas Moulisha ${ }^{1^{*}}$, Mandal Nirup Bikash ${ }^{2}$, Palit Partha ${ }^{2}$, Ghosh Ashoke \\ Kumar $^{3}$, Bannerjee Sukdeb ${ }^{2}$ and Haldar Pallab.Kanti ${ }^{4}$ \\ ${ }^{1}$ Bengal Institute of Pharmaceutical Sciences, Kalyani, Nadia-741 235, ${ }^{2}$ Indian Institute of Chemical Biology, \\ Department of Steroids and Terpenoids Chemistry, Jadavpur-700 032, , , Bengal School of Technology, Delhi Road, \\ Sugandha, Dt. Hooghly, PIN: 712 102, " Division of Pharmacology, Department of Pharmaceutical Technology, \\ Jadavpur University, Kolkata - 700 032, West Bengal, India.
}

\begin{abstract}
Purpose: Dregea volubilis Benth, commonly known as Jukti in Bengal, is used in the treatment of boils and abscesses from ancient times. The purpose of this study is to elucidate the active compounds and as well as their anti-leishmanial and anti-tumour activities.

Methods: Dried and crushed fruits of Dregea volubilis were extracted by petroleum ether $\left(40-60^{\circ} \mathrm{C}\right)$; the best solvent system had first been verified by analytical Thin Layer Chromatography (TLC). The extract was subjected to TLC and column chromatography (CC) to isolate the pure compounds. Spectra data were obtained by Infra Red pectroscopy, Mass Spectroscopy and Nuclear Magnetic Resonance Proton Magnetic Resonance (PMR), Carbon Magnetic Resonance (CMR) and Distortionless Enhancement by Polarization Transfer (DEPT) - for structure elucidation of the isolated compound(s). One of the compounds isolated was screened for anti-leishmanial activity against promastigotes of Leishmania donovani and anti-tumour activity on K562 leukemic cell line.

Results: A pentacyclic triterpenoid compound was isolated and designated as taraxerone, and then characterized as d-friedoolean-14-en, 3 one together with B-sitosterol and a long chain lipid fraction.. This compound showed in vitro anti-leishmanial activity against promastigotes of Leishmania donovani (strain AG 83) and anti-tumour activity on K562 leukemic cell line.

Conclusion: A pentacyclic triterpenoid compound designated as taraxerone and characterized as $D$ friedoolean-14-en, 3 one together was successfully isolated. The structure was determined on the basis of spectral analysis (IR, MASS, NMR (PMR, CMR and DEPT) and the compound demonstrated in vitro anti-leishmanial and anti-tumour activities.
\end{abstract}

Keywords: Dregea volubilis, Pentacyclic triterpenoid, Taraxerone, Spectroscopy (IR, MASS, CMR, PMR, DEPT), Anti-leishmanial, Anti-tumour.

*Corresponding author: E-mail: moulisha_biswas@yahoo.co.in Tel: +91-33-25211273; +91-9831354803(M); Fax: $+91-33-25891742$ 


\section{Introduction}

Dregea volubilis (Linn. f.) Benth ex. Hook f. Syn: Wattakaka volubilis (Linn. f.) Stapf; Marsedenia volubilis (Cooke) belongs to the family Asclepiadaceae and is commonly known as "Jukti" in Bengal. It is a tall woody climber with height of $11 \mathrm{~m}$ and a girth of 95 $\mathrm{cm}$ with densely lenticulate branches. It occurs throughout the hotter parts of India and Car Nicober Islands ascending to an altitude of $1500 \mathrm{~m}^{1}$. The parts of the plant are used traditionally as medicines. The juice of the plant is used as a sternutatory and the leaves are employed in the treatment of boils and abscesses. The roots and tender stalks are used as emetic and expectorant. It has been reported that the ethyl alcohol (50\%) extract of the plant has activity on the central nervous system as well as anti-cancer activity against Sarcoma 180 in mice ${ }^{1}$, the reported maximum tolerated dose being $500 \mathrm{mg} / \mathrm{kg}$ body weight of albino mice. Two pregnane glycosides, dregeosides Ap1 and $A_{01}$, isolated from this plant, collected from Thailand, showed antitumor activities against melanoma B-16 in mice $^{1}$. Reichstein and co- workers ${ }^{2}$ studied the components of the seeds of the plant and deduced the structure of drevogenins $A, B, D$ and $P$. Subsequently, the isolation and characterization of twelve polyhydroxy $C / D$ cis-pregnane glycosides from the same plant collected from Thailand was reported ${ }^{2,3}$. Isolation of $\beta$ - sitosterol, kaempherol-3galactoside, a 2-deoxy sugar, drevogenin $A$, drevogenin $\mathrm{P}, \mathrm{D}$-cymarose and L-olendrose from the plant has also been reported ${ }^{4,5}$.

The objective of this work is to undertake the isolation and characterization of a novel pentacyclic triterpenoid compound from the extract of Dregea volubilis in order to evaluate its anti-leishmanial activity as well as its antitumour activity on K562 leukemic cell line. Previously taraxerone was isolated from the plant, Myrica rubra ${ }^{5,6}$, and shown to have inhibitory activity on reverse transcriptase on human immunodeficiency virus and of kinesin motor proteins ${ }^{7}$.

\section{Experimental}

\section{Plant material}

The plant material, Dregea volubilis, was collected from Indian Botanic Garden, Howrah, West Bengal, India. A voucher specimen (voucher no $\mathrm{CNH} / \mathrm{I}-\mathrm{I} /(267) / 2008$ ) was preserved for future reference at Bengal Institute of Pharmaceutical Sciences, Kalyani, Nadia, India.

\section{Extraction and isolation}

The shade-dried powdered fruits of Dregea volubilis $(2.4 \mathrm{~kg})$ were extracted successively with petroleum ether $(3 \times 8 \mathrm{~L})$ at $40-45^{\circ} \mathrm{C}$ temperature. The combined extract was concentrated and $18 \mathrm{~g}$ of the extract was applied to a column of silica gel $60(400 \mathrm{~g})$ and washed with $100 \%$ petroleum ether. Gradient elution was carried out with a mixture of petroleum ether and chloroform (1:9, 1:4, 3:7, $2: 3$ and $1: 1$, respectively). A total of 72 fractions $(50 \mathrm{ml})$ were collected. Fractions giving similar spots on TLC (obtained by spraying with Libermann - Buchard reagent) were combined. Fractions eluted with chloroform-petroleum ether (1:4) were also combined and subjected to rechromatography over silica gel $(20 \mathrm{~g})$. The fractions $(15 \mathrm{ml}$ lots $)$ were eluted with chloroform-petroleum ether mixture $(3: 7)$ to furnish taraxerone $(1.5 \mathrm{~g})$.

\section{Thermal and spectroscopic studies}

All melting points were measured on Yanagimoto micromelting apparatus and are uncorrected. Infra-red (IR) spectra were determined using JASCO 7300 FTIR spectrometer. Optical rotations were measured using a JASCO DIP-370 digital polarimeter. Nuclear magnetic resonance (NMR) spectra - both proton magnetic resonance (PMR) and carbon magnetic resonance $(\mathrm{CMR})$ - were recorded at 500 and $300 \mathrm{MHz}$, respectively, using a Jeol ECP-500 spectrometer in $\mathrm{C}_{5} \mathrm{D}_{5} \mathrm{~N}$ with $\mathrm{TMS}$ as the 
internal standard. High resolution fast atom bombardment mass spectroscopy (MASS) was performed on a JEOL MS-700 mass spectrometer. TLC was carried out on silica gel $60 \mathrm{~F}_{254}$ and the spots were visualized by spraying with Libermann- Buchard's reagent followed by heating. Silica gel (silica gel 60120 mesh, Merck) was used for column chromatography (CC).

\section{Parasite culture and growth conditions for anti-leishmanial activity}

Leishmania donovani strain AG 83 was collected $^{8}$ and maintained in golden hamsters by serial passage. After 2 months, the hamster was sacrificed and its spleen was isolated and macronized. Approval (no: $367001 /$ C/CPCACA) for the animal experiment was given by the Ethical Committee of Jadavpur University, Kolkata, West Bengal, India. The spleenic culture was made in Medium-199 (L-glutamine with Hepes buffer without $\mathrm{NaHCO}_{3}$ ) supplemented with $10 \%$ fetal bovine serum of $\mathrm{pH} 7.2$. The logarithm phases of promastigotes $\left(2 \times 10^{6}\right.$ cells $/ \mathrm{ml}$ ) were incubated with or without the compounds along with Medium-199 at $22{ }^{\circ} \mathrm{C}$. The tested compounds were dissolved in $0.2 \%$ dimethyl sulphoxide (DMSO), these compounds were added to the culture in graded dose of $3 \mu \mathrm{g} / \mathrm{ml}, 5 \mu \mathrm{g} / \mathrm{ml}, 10 \mu \mathrm{g} / \mathrm{ml}, 15$ $\mu \mathrm{g} / \mathrm{ml}$ and $30 \mu \mathrm{g} / \mathrm{ml}$. After $2 \mathrm{~h}$ of treatment, the tubes were centrifuged at $8000 \mathrm{~g}$ for about 10 min. The supernatant was decanted and the pellets were washed with $20 \mathrm{mM}$ phosphate buffer saline (PBS). Each pellet was dissolved in $100 \mu \mathrm{l}(2 \mathrm{mg} / \mathrm{ml})$ MTT solution, the tubes incubated at $22^{\circ} \mathrm{C}$ for $4 \mathrm{~h}$ and then centrifuged at $8000 \mathrm{~g}$ for $10 \mathrm{~min}$. The resulting pellets were dissolved in $500 \mu \mathrm{l} 0.2 \%$ DMSO and the absorbance measured spectrophotometrically at $570 \mathrm{~nm}$. Lysis of promastigotes (\%) by the compounds was calculated by the standard formula of Tim Mosmann ${ }^{8}$, as shown in Eq 1.

$\%$ lysis $=100-\{($ test - positive control $) /($ control - positive control $)\} \times 100 \ldots(1)$
The $I_{50}$ dose was evaluated by linear regression analysis using Graph Pad Prism 3 software.

\section{Cell culture and growth conditions for anti- tumour activity}

The human chronic myelogenous leukemia cell line K562 was obtained from a patient in blast crisis of chronic myeloid leukemia. The cells were grown in RPMI-1640 medium supplemented with $10 \%$ foetal calf serum (Gibco,USA), air and $5 \% \mathrm{CO}_{2}$. The tested compound contained $1 \times 10^{6} \mathrm{cells} / \mathrm{ml}$ at graded $2 \mathrm{mML}$ glutamine and $50 \mu \mathrm{g} / \mathrm{ml}$ gentamycin at $37^{\circ} \mathrm{C}$ in a fully humidified atmosphere of $95 \%$ dose. After $18 \mathrm{~h}$ of incubation at $37^{\circ} \mathrm{C}$ in $5 \%$ $\mathrm{CO}_{2}$ incubator, all tubes were centrifuged at $8000 \mathrm{~g}$ for $10 \mathrm{~min}$. The supernatant was decanted and the pellets were washed with $20 \mathrm{mM}$ of PBS. Each pellet was dissolved in $100 \mu \mathrm{l}(2 \mathrm{mg} / \mathrm{ml})$ MTT solution incubated at $22^{\circ} \mathrm{C}$ for $4 \mathrm{~h}$ and centrifuged at $8000 \mathrm{~g}$ for 10 min. The resulting pellets were dissolved in $500 \mu \mathrm{l}$ DMSO and the absorbance measured spectrophotometrically at 500nm. Lysis (\%) of K562 cells by the compound was calculated by standard formula ${ }^{8}$ (Tim Mosmann), the formula is $[100-\{$ (test - positive control)/(control - positive control)\}] $\times 100$. The $I_{50}$ dose was evaluated by linear regression analysis using Graph Pad Prism 3 software.

\section{Results}

In vitro anti-leishmanial activity against Leishmania donovani (strain AG83) and anticancer activity on K562 leukemic cell line have been shown from the isolated compound in the petroleum ether extract of Dregea volubilis fruits. The active fraction of the extract of Dregea volubilis fruits and identified as a pentacyclic triterpenoid compound, namely, taraxerone whose structure is shown Fig 1. The compound was crystallized from methanol as colorless crystalline needles with a melting point (m.p.) of $239-242^{\circ} \mathrm{C}$, [a]D+9.72 (c, 1.04, $\mathrm{CHCl}_{3}$ ). The compound gave a brownish violet color for the 
Libermann-Burchard test, indicating the presence of triterpene skeleton. The compound exhibited in its IR spectrum absorption bands at 1708, 1473, 1375, 996 and $818 \mathrm{~cm}-1$ attributed to a keto group and an olefinic double bond. MASS spectrum displayed a sodiated molecular ion peak at $\mathrm{m} / \mathrm{z} 447.39$, indicating the molecular weight of the compound to be 424 and its molecular formula, $\mathrm{C}_{30} \mathrm{H}_{48} \mathrm{O}$. The ${ }^{1} \mathrm{H}$ NMR spectrum of the compound displayed eight methyl signal (all singlets) at $\delta 0.83,0.90,0.91,0.95,1.06$, $1.08,1.08$ and 1.14. The spectrum also showed one double doublet at $\delta 5.56(\mathrm{~J}=7.8$ and $2.7 \mathrm{~Hz}$ ) ascribed to an olefinic proton. The ${ }^{13} \mathrm{C}$ NMR spectrum of the compound indicate the presence of thirty carbons in the compound. All the carbon resonances were assigned by multiplicity information obtained from distortionless enhancement by polarization transfer (DEPT). The spectrum revealed the presence of eight methyls, ten methylenes, four methines and eight quaternary carbons, including signals appropriate for one trisubstituted double bond and a carbonyl function. The singlet at $\delta 217.9$ unambiguously demonstrated the presence of a carbonyl group attached to a six-member ring. The singlet at $\delta 158.0$ and doublet at $\delta$ 117.6 can be assigned to C-14 and C-15, respectively, indicating that the compound belongs to taraxerone or $\mathrm{D}$ - friedooleananes group.

From the foregoing evidence, it can be said that the triterpene core of the compound is $D$ friedoolean-14- en, 3 one as illustrated in Figure 1.

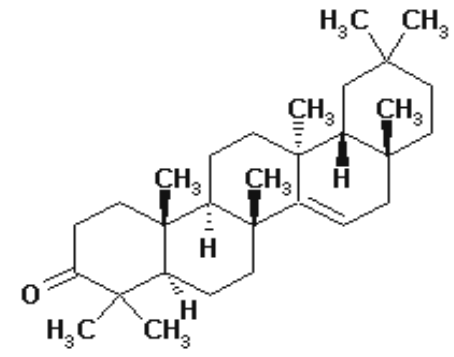

Figure 1: Structure of taraxerone (Dfriedoolean-14- en, 3 one)
Table 1: ${ }^{13} \mathrm{C}$ NMR data

\begin{tabular}{cc}
\hline $\begin{array}{c}\text { Carbon } \\
\text { number }\end{array}$ & Taraxerone \\
\hline 1 & $217.9(\mathrm{~s})$ \\
2 & $158.0(\mathrm{~s})$ \\
3 & $117.6(\mathrm{~s})$ \\
4 & $56.2(\mathrm{~d})$ \\
5 & $49.2(\mathrm{~d})$ \\
6 & $49.1(\mathrm{~d})$ \\
7 & $48.0(\mathrm{~s})$ \\
8 & $41.0(\mathrm{t})$ \\
9 & $39.3(\mathrm{~s})$ \\
10 & $38.7(\mathrm{t})$ \\
11 & $38.1(\mathrm{t})$ \\
12 & $38.1(\mathrm{~s})$ \\
13 & $37.9(\mathrm{~s})$ \\
14 & $37.1(\mathrm{t})$ \\
15 & $36.2(\mathrm{~s})$ \\
16 & $35.5(\mathrm{t})$ \\
17 & $34.5(\mathrm{t})$ \\
18 & $34.0(\mathrm{t})$ \\
19 & $33.8(\mathrm{q})$ \\
20 & $33.5(\mathrm{t})$ \\
21 & $30.3(\mathrm{q})$ \\
22 & $30.2(\mathrm{q})$ \\
23 & $29.2(\mathrm{~s})$ \\
24 & $26.5(\mathrm{q})$ \\
25 & $26.0(\mathrm{q})$ \\
26 & $21.9(\mathrm{q})$ \\
27 & $21.7(\mathrm{q})$ \\
28 & $20.4(\mathrm{t})$ \\
29 & $17.8(\mathrm{t})$ \\
30 & $15.2(\mathrm{q})$ \\
\hline & \\
\hline
\end{tabular}

\section{Anti-leishmanial activity}

Table 2 shows that taraxerone inhibited growth of Leishmania promastigotes in a dose-depended manner

\section{Anti-tumour activity}

The results of the anti-tumour test are indicated in Table 3. As the dose of the drug increased, the proportion of cells lysed rose from 38 to $87 \%$. 
Table 2: Activity of taraxerone against Leishmania promastigotes culture $\left(2 \times 10^{6}\right.$ cells/ml)

\begin{tabular}{rrr}
\hline $\begin{array}{l}\text { Drug dose } \\
(\mu \mathrm{g} / \mathrm{ml})\end{array}$ & $\begin{array}{l}\text { Lysis (\%) with } \\
\text { respect to } \\
\text { control }(0.1 \% \\
\left.\mathrm{CHCl}_{3}\right)\end{array}$ & $\begin{array}{l}\mathrm{IC}_{50} \text { value } \\
\text { for } \\
\text { Taraxerone }\end{array}$ \\
\hline 3 & 51.34 & \\
5 & 57.2 & 3.18 \\
10 & 66.34 & \\
15 & 72.7 & \\
30 & 90.8 & \\
\hline
\end{tabular}

Table 3: Anti-tumour data for taraxerone

\begin{tabular}{ccc}
\hline $\begin{array}{c}\text { Drug dose } \\
(\mu \mathrm{g} / \mathrm{ml})\end{array}$ & $\begin{array}{c}\text { Lysis }(\%) \\
\text { with respect } \\
\text { to control } \\
\left(0.1 \% \mathrm{CHCl}_{3}\right)\end{array}$ & $\begin{array}{c}\mathrm{IC}_{50} \\
\text { value for } \\
\text { taraxerone }\end{array}$ \\
\hline 5 & 38.4 & 7.401 \\
10 & 61.3 & \\
15 & 87.4 & \\
\hline
\end{tabular}

\section{Discussion}

Our studies indicate that the non-polar content of the fruits of Dregea volubilis Benth yielded a pentacyclic triterpenoid designated as taraxerone and characterized as Dfriedoolean-14-en, 3 one the structure was determined on the basis of IR, MASS, NMR (PMR, CMR and DEPT) spectroscopic analysis On the other hand, previous studies on the flowers of this plant showed the presence of polyoxy- and polyhydroxyl pregnane glycosides ${ }^{1,2,3}$ which constitute the steroid moiety.

That the isolated compound exhibited in vitro anti-leishmanial activity against promastigotes of Leishmania donovani (strain AG 83) and anti-cancer activity on K562 leukemic cell line, is instructive. This work buttresses the need to continue to investigate traditional remedies with a view to isolating their active constituents since an estimated $60 \%$ of people living in developing countries depend on traditional medicine for their primary health care. Modern therapy derived from medicinal herbs promises a practical approach to development of effective and affordable drugs. However, further work (including in vivo studies) will still be required to establish the effectiveness and full potentials of the taxerone isolated from Dregea volubilis Benth.

\section{Conclusion}

The non-polar portion of the fruit extract of Dregea volubilis Benth contains a pentacyclic triterpenoid compound, taraxerone. The compound demonstrated anti-leishmanial and anti-tumour activities.

\section{Acknowledgment}

The authors are grateful to Mr. Rajendra Mahato, Steroid and Terpenoid Chemistry Division, Indian Institute of Chemical Biology, for assistance during this work.

\section{References}

1. Panda N, Banerjee S, Mandal NB, Sahu NP. Pregnane Glycosides. Nat Prod Commun, 2006; 665-669.

2. Sahu NP, Panda N, Mandal NB, Banejee S, Koike K, Nikadio T. Polyoxy Pregnane Glycosides from the Flowers of Dregea Volubilis. Phytochemistry, 2002; 61: 383-387.

3. Panda N, Mandal NB, Banerjee S, .Sahu NP, Koike K, Nikaidio T, Weber M, Luger P. Polyhydroxy Pregnanes from Dregea volubilis.. Phytochemistry, 2003; 61: 8400-8405.

4. Mahato SB, Nandy AK, Roy G. Triterpenoids. Phytochemistry, 1992; 31: 2199-2205.

5. Nobuo $S$, Inoue T. Triterpenoids from Myrica rubra. Phytochemistry, 1987; 26: 217-221.

6. Mahato $S B$, Kumar $A P .{ }^{13} C$ NMR Spectra of Pentacyclic Triterpenoids- $A$ compilation and some salient features. Phytochemistry, 1994; 37: 1517-1522.

7. Morais G, Watanabe M, Mataka S, Ideta K, Thiemann T. Areno annelated Estranes by Intermolecular Cycloaddition. $9^{\text {th }}$ Int Conf Synth Org Chem, Fukuoka, Japan, ECSOC-9, 2005, 309-311.

8. Ghosh AK, Rakshit MM, Ghosh DK. Effect of berberin chloride on Leishmania donovani. Ind $J$ Medicinal Res, 1983; 78: 407-411. 